O Open Access Full Text Article

REVIEW

\title{
Assessment of acceptability and ease of use of gelling fiber dressings in the management of heavily exuding wounds
}

This article was published in the following Dove Press journal:

Chronic Wound Care Management and Research

\section{Gurudutt Naik \\ Keith G Harding}

Department of Wound Healing, Welsh Wound Innovation Centre, Rhondda Cynon Taf, Wales, CF72 8UX, UK
Correspondence: Gurudutt Naik

Welsh Wound Innovation Centre, Rhodfa

Marics, Ynysmaerdy, Pontyclun, Rhondda

Cynon Taf, Wales, CF72 8UX, UK

Tel +44 I443443870

Email NaikG@cf.ac.uk

\begin{abstract}
Optimal exudate management plays an important role in wound healing. Choosing the right methods for this purpose is the key in achieving successful outcomes in the management of chronic wounds. Gelling fiber dressings are a class of dressing that forms a gel when they come into contact with wound exudate. This property allows them to effectively lock in excess fluid and at the same time provides enough moisture for healing to progress. Alginate and chitosan are naturally occurring gelling agents used in dressings, whereas carboxymethyl-cellulose, also called carmellose, is synthetically produced. This article reviews the use of these gelling fiber dressings in chronic wounds with a particular focus on their ability to manage wound exudate effectively.
\end{abstract}

Keywords: wound healing, wound management, chronic wounds, hydrofiber, hydrocolloid fiber, wound fluid

\section{Introduction}

Management of chronic wounds has been a major therapeutic challenge in most health systems worldwide. This problem is likely to escalate further within the western world with its ageing population and increasing prevalence of conditions that impede wound healing. ${ }^{1-5}$ Nearly 2.2 million wounds were being managed by the National Health System (NHS) in the year 2012/2013 with a $£ 5.3$ billion spend; accounting for 18.6 million practice nurse visits, 10.9 million community nurse visits, 7.7 million GP visits, and 3.4 million hospital outpatient visits. ${ }^{6}$ The total cost of managing patients with wounds originating in primary care in Wales accounted for nearly $6 \%$ of the total expenditure of the health service at an average cost of $£ 1,727$ per patient. ${ }^{3}$ The cost to patients due to loss of quality of life due to chronic wounds and its complications cannot be easily measured, but there is no doubt that this is a significant one. People living with chronic wounds as such suffer from various psychological, emotional, and physical problems and malodourous exudate from the wound itself can further add to the patient's distress and the perception of pain. ${ }^{7}$ Heavy exudate from wounds is one of the main reasons for more frequent dressing changes necessitating extra nurse visits and consultations.

In this article we focused on the acceptability of "gelling fiber" dressings in managing heavily exuding wounds. We have used the term gelling fiber for dressings manufactured using alginates or chitosan or carboxymethyl-cellulose (CMC), also known as hydrofibers. These products are similar in their actions and primarily 
absorb wound exudate by forming a gel when they come into contact with fluid. There are three varieties of gelling agents that are spun into fibrous form and used in wound contact dressings. Two of them, i.e., alginate and chitosan are naturally occurring gelling agents. CMC, also called carmellose, is synthetically produced.

Information for this article was gathered by literature search of the following databases:

1. NICE database evidence search;

2. Cochrane database for systematic reviews;

3. MEDLINE and EMBASE on OVID platform.

Searches using appropriate combinations of keyword terms; "Gelling Fibre", "Hydrofibre", "Hydrocolloid Fibre", "Protease Modulators", "Alginates", "Chitosan", and "Wound Dressings" were carried out.

\section{Managing chronic wounds}

Managing specific wounds depends on the underlying pathology. In general, managing complex and chronic wounds requires a comprehensive assessment of the whole patient and due consideration must be given to all the underlying local and systemic factors that impede wound healing. Once these factors are addressed the focus should be on preparing the wound bed to heal. The concept of wound bed preparation (WBP) provides clinicians with a framework to address abnormalities that impair wound healing. It has been defined as:

"The global management of the wound to accelerate endogenous healing or to facilitate the effectiveness of other therapeutic measures."

The wound bed should be free from infection, necrotic or fibrinous tissue and exudate, and have an adequate blood supply to ensure tissue oxygenation to stimulate endogenous healing. ${ }^{9}$ The local treatment options currently available for managing wounds can be broadly classified into; dressings, drugs, devices, surgery, and biologic therapies, and patients may require a combination of these to achieve healing.

\section{Wound exudate}

Wound exudate can be loosely described as "what is coming out of the wound", "wound fluid", "wound drainage", and "an excess of normal fluid". It is produced in response to complicated interactions and related to wound etiology, wound healing physiology, wound environment, and compounding pathological processes such as infections and inflammation. Wound exudate is not necessarily detrimental to wound healing and can help prevent the wound bed from drying out. Moisture in the wound bed promotes better wound healing by aiding several steps involved; such as epithelial cell migration and faster epithelialization. ${ }^{10}$ However, when the exudate levels are excessive this can be detrimental to the wound and surrounding skin. There is evidence that higher levels of exudate can be an indicator of wound pain status. ${ }^{11}$ Wound exudate increases in response to colonization or localized wound infection causing further increase in pain levels from the wound site. ${ }^{12}$ The other main problem is peri-wound skin damage, also called moistureassociated skin damage (MASD). ${ }^{13}$ Figures 1 and 2 show MASD in the skin surrounding the wound and also maceration of epithelial skin islands. This is caused by prolonged exposure of the wound and surrounding skin to moisture and potential irritants in the wound exudate with resulting softening and maceration of the skin followed by erosion of the epidermis which can increase the wound surface area. ${ }^{13}$ An

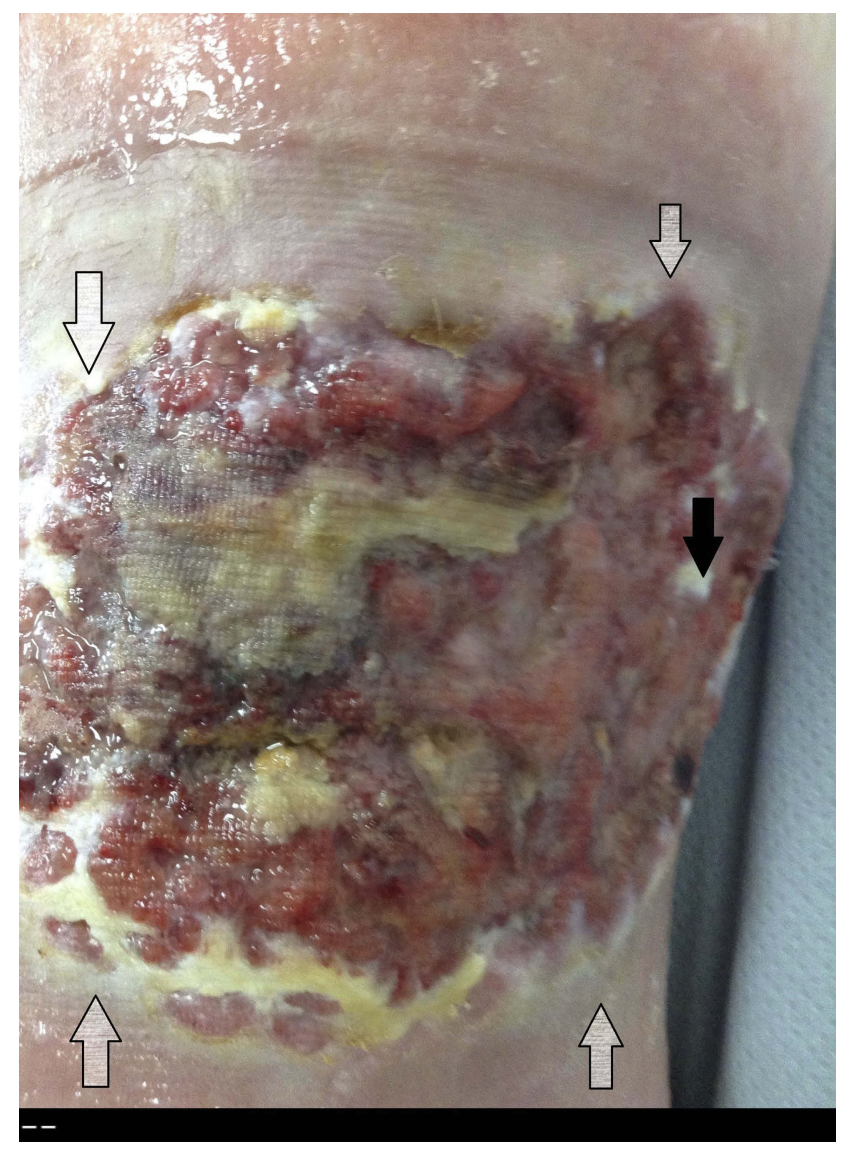

Figure I Wounds with heavy exudate and resultant moisture-associated skin damage (MASD). Gray arrows show MASD in surrounding skin and black arrows show damaged epithelial islands. 


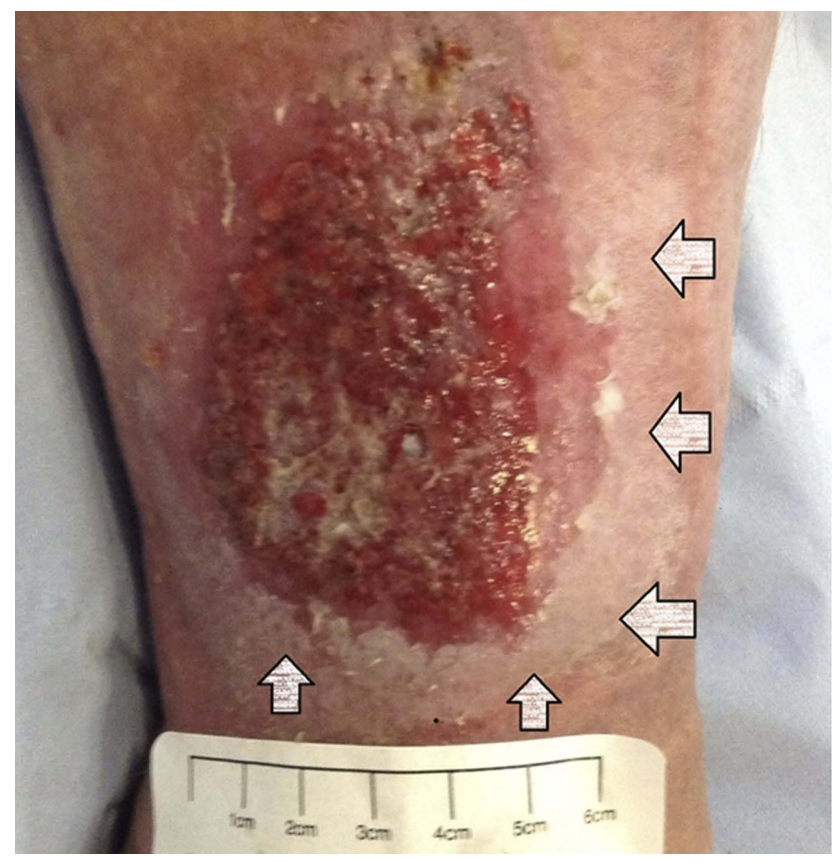

Figure 2 Wounds with heavy exudate and resultant moisture-associated skin damage (MASD). Gray arrows show MASD in surrounding skin.

integrated approach to manage exudate is the key factor to protect the peri-wound skin from excessive moisture and at the same time maintaining an adequately moist environment in the wound bed to promote wound healing. " "The challenge for wound management is to get the balance of exudate right - neither too dry nor too wet." ${ }^{.15}$ Managing exudate in practice is routinely done by using appropriate dressings that can absorb excessive fluid whilst maintaining a moist environment. In patients with heavily exuding wounds, topical negative pressure (TNP) therapy may be considered. Several clinical trials have reported improved outcomes with TNP, but most studies have been assessed as methodologically flawed and currently there is still uncertainty about its effectiveness. ${ }^{16-18}$ In some cases, fluid collection devices such as ostomy bags could be used, especially if there is an underlying fistula feeding the wound.

\section{Dressings in managing wound exudate}

Gauze bandages for wounds have been used since ancient times and firmly established for covering wounds by the 5 th century BCE. ${ }^{19,20}$ The use of gauze for dressings is still prevalent in many countries. These dressings allow evaporation of wound fluid, which results in a dry wound bed leading to adherence of the dressing material and potentially delayed wound healing. An improved understanding of wound healing biology and WBP led to the development of advanced dressings, designed to actively facilitate wound healing either on their own or by releasing bioactive constituents. Ideally, dressings should promote a wound environment that is conducive to the healing process. Box 1 enumerates the main features of ideal dressings used to treat chronic wounds.

There are several classes of dressings available to manage wound exudate. In our opinion, four classes of dressings that are currently available can be suitably used in heavily exuding wounds (Table 1) Systematic reviews have only shown low and very low quality evidence that some advanced dressings (for example, hydrocolloid, hydrogel, film, and foam dressings) are more effective than simple conventional ones. ${ }^{21}$ Well-designed randomized controlled trials that studied gelling fiber dressings are sparse.

\section{Synthetic gelling fiber: CMC (or carmellose or hydrofiber)}

Cellulose is the most abundant naturally occurring fiber with good tensile strength. Celluose can be structurally changed to form $\mathrm{CMC}$ that can form a gel when the fibers come into contact with fluids. ${ }^{22}$ This characteristic of CMC helps lock in excessive exudate when used in wound dressings. The wound exudate along with inflammatory cells, debris, and metallo-proteases are trapped in the fibers promoting autolytic debridement. ${ }^{23}$ Toward the

Box I Characteristics of an ideal dressing

The ideal dressing should:

- Maintain a moist environment whilst removing excess exudate

- Cover and protect the wound bed

- Be comfortable and conformable

- Be free from toxic and allergenic substances

- Maintain the optimum temperature

- Promote autolysis of slough/debris

- Be impermeable to bacteria

- Allow gaseous exchange

- Come off easily without causing trauma to the wound bed

- Have adequate tensile strength especially when used as ribbon/wick dressings in wound cavities

- Not require frequent changes and be cost-effective

- Have a long shelf-life and be easily disposable 
Table I Dressing types suitable for heavily exuding wounds

\begin{tabular}{|c|c|c|}
\hline $\begin{array}{l}\text { Type of } \\
\text { dressing }\end{array}$ & Component & Action \\
\hline \multicolumn{3}{|c|}{ Natural gelling fibers } \\
\hline Chitosan fiber & $\begin{array}{l}\text { Calcium alginate or sodium calcium alginate derived from brown } \\
\text { seaweed } \\
\text { Treated chitin (linear polysaccharide consisting of glucosamine and } \\
\mathrm{N} \text {-acetyl glucosamine chains) from shells of shrimps and other } \\
\text { crustaceans }\end{array}$ & $\begin{array}{l}\text { - Partly dissolves on contact with exudate forming a } \\
\text { hydrophilic gel } \\
\text { - Has high absorbent capacity up to I5-20 times their } \\
\text { weight } \\
\text { - Promotes autolytic debridement and also has hemo- } \\
\text { static effect when needed } \\
\text { - Fibers lock in fluid to form a clear gel that reduces } \\
\text { the lateral spread } \\
\text { - Creates positive charge and interacts with negatively } \\
\text { charged molecules such as blood cells, lipids, and } \\
\text { bacteria } \\
\text { - Promotes autolytic debridement and has hemostatic } \\
\text { effect }\end{array}$ \\
\hline \multicolumn{3}{|c|}{ Synthetic gelling fibers } \\
\hline $\begin{array}{l}\text { Hydrocolloid- } \\
\text { fibrous or gel- } \\
\text { ling fiber }\end{array}$ & Modified carmellose fibers & $\begin{array}{l}\text { - Absorbs fluid when in contact with wound fluid to } \\
\text { form a gel } \\
\text { - Allows moist wound healing } \\
\text { - Promotes autolytic debridement }\end{array}$ \\
\hline \multicolumn{3}{|c|}{ Other absorbent dressings } \\
\hline $\begin{array}{l}\text { Superabsorbent } \\
\text { polymers }\end{array}$ & $\begin{array}{l}\text { Polymers on polyacrylates based on baby diaper/female hygiene } \\
\text { product technology } \\
\text { Polyurethane foam }\end{array}$ & $\begin{array}{l}\text { - High density ionic charges which account for hydro- } \\
\text { active properties } \\
\text { - Ideal for absorbing large amounts of fluid from the } \\
\text { wound } \\
\text { - Physically draws up fluid in the foam by capillary } \\
\text { action }\end{array}$ \\
\hline
\end{tabular}

end of the last century, dressings made of CMC fiber were first launched. ${ }^{23} \mathrm{CMC}$ dressings are the most widely used dressings in today's clinical practice. Silver-impregnated CMC fibers that can enhance the antimicrobial property of the dressings, are also available and widely used in wound care practice. Based on 2015 data supplied by NHS supply chain, NHS Trusts are using nearly 3.5 million gelling fiber dressings which accounts for nearly $40 \%$ of the total $£ 8$ million spent on wound care products annually. ${ }^{24}$

One of the first multi-center randomized trials of 44 patients with exuding and chronic leg ulcers compared a then newly launched (in the year 1997) CMC dressing with alginate dressing. ${ }^{25}$ The study found a statistically significant difference between treatment groups in the mean "wear time" with CMC dressings faring better in terms of absorptive capacity and lasting longer. The authors however admitted the small number of participants (44) limited the study in providing meaningful conclusions. Later, the UK hydrofiber leg ulcer study, which was a large multi-center randomized clinical trial comparing $\mathrm{CMC}$ dressings with alginate dressings, resulted in an overall global outperformance of CMC dressings compared to alginate dressings. CMC did better in all outcomes including healing, ability to handle exudate, ease of application, ease of removal, and cost-effectiveness. In another randomized comparative trial of post-surgical (hipreplacement) wounds where alginate dressings were compared to CMC dressings, the results showed significantly less occurrences of skin blistering and damage with alginate dressings. ${ }^{26}$

Several product evaluation studies and case studies have shown that $\mathrm{CMC}$ dressings are useful in most types of exuding wounds. CMC dressings impregnated with silver were found to be an appropriate dressing choice in 
managing infected pressure ulcers with high exudate levels in one such case study. In this study, the patient pain scores showed significant improvement with the use of the dressing. ${ }^{27}$ Moderately to highly exuding venous leg ulcers with clinical signs of infection have also been shown to benefit from the use of silver-impregnated CMC dressings in another study. ${ }^{28}$ These dressings optimized exudate levels effectively and were found to be acceptable in all patients taking part in the study. In another case series of patients with heavily exuding wounds of different etiologies, CMC dressings were found to reduce exudate levels over a 4-week period in $75 \%$ of the patients and $99 \%$ of the wounds did not show peri-wound skin damage. ${ }^{29}$ All patients were satisfied with the comfortability of the dressing. CMC hydrofiber dressings have also been found to be a safe and effective method of treatment for complex surgical and chronic wounds where excess exudate is effectively "mopped up" ${ }^{30}$ We also found a case report of a very satisfied rheumatoid arthritis patient with chronic venous foot ulcers, treated with CMC dressings. ${ }^{31}$ Improved quality of life, mobility, reduced wound odour and exudate were noted by the treating clinicians and the patient.

\section{Naturally occurring gelling fiber Alginates}

Alginate dressings have been in use for nearly 2 decades. This class of dressing is the oldest of the advanced dressing types, primarily used for their ability to manage wound exudate effectively. They also have an innate hemostatic effect and can be used to stop minor bleeding complications from wounds; for example after a wound biopsy. Alginates used in dressings are made of alginic acid from seaweed and are combinations of mannuronic and guluronic acid fibers. The combination used characterizes the quality and the wet tensile strength of the dressing. ${ }^{32}$

Most studies that have tested alginates demonstrated that they are valid and safe dressing choices due to their absorbent capacity, hemostatic effect, promotion of autolytic debridement, and their ability to maintain a moist healing environment. We found two randomized trials that found alginates superior to gauze dressings in its absorptive capacity, hemostatic effect, comfortability, and time to healing. ${ }^{33,34}$ The wounds were acute surgical wounds of donor sites after a split skin graft. One randomized comparative study resulted in better outcomes for pain and ease of use for the dressing with foam adhesive compared to alginate dressings in split skin graft donor site wounds. ${ }^{35}$ For chronic non-infected pilonidal sinuses, both foam sheet dressings and alginate dressings were found to be easy to use, effective, and acceptable to patients and clinicians. ${ }^{36}$ The randomized studies comparing alginates with CMC fiber dressings were mentioned in the synthetic gelling fiber section.

The searches also yielded two non-comparative studies. One study showed the effect of alginate dressings in diabetic foot ulcers and reported overall reduction in ulcer area, overall good management of exudate with reduction over time, and in general patients found the dressing comfortable. ${ }^{37}$ The other non-comparative study used sequential dressings of alginate (initial 4-6 weeks) and foam dressings (later 6-8 weeks) for pressure ulcers in spina-bifida patients with good results. ${ }^{38}$ Authors proposed an interesting probable explanation for the benefit seen, ie, initial use of alginates promotes autolytic debridement followed by foam that probably enhances granulation. Both dressings managed exudate well.

\section{Chitosan}

The latest addition to the gelling fiber class of dressings is made from a naturally occurring bio-degradable product called chitosan. Chitosan is the second most abundant naturally occurring carbohydrate polymer derived from chitin present in the shells of crustaceans such as snow crab and shrimps. ${ }^{39}$ Chitosan has the following properties; ${ }^{40}$

- biocompatible,

- bio-degradable,

- non-toxic,

- antimicrobial,

- hydrating,

- retains fibroblast growth factors,

- stimulates dermal fibroblasts, cell adhesion,

- promotes collagen deposition.

Chitosan dressings are not yet freely available, but several studies have yielded positive results and we may see this class of dressing emerging in the market soon. We found only one randomized trial of 85 participants with diabetic or pressure or leg ulcers. ${ }^{41}$ A dressing made from a combination of alginate and chitosan was used in the intervention group which was compared to conventional dressings. The difference between the two groups in the number of wounds that healed was statistically significant with the intervention group doing better. There were significant 
drop-outs in the study; with 30 out for 31 drop-outs from the control arm which received conventional dressings. Chiotsan has been used in case studies of wounds with deep bone infections, diabetic foot ulcers, arterial ulcers, post-surgical abdominal wounds, and infected pace-maker wounds. The dressing has been shown to manage exudate very well in addition to reducing bio-burden in infected wounds. ${ }^{42-44}$ The largest multi-center evaluation was reported by Mason and Clarke. ${ }^{45}$ This study was undertaken by 15 clinicians in eleven centers across Staffordshire in the UK. The sample size in this study was 18 in total and $61 \%$ of patients' wounds healed within 4 weeks. Quality of life aspects such as reduction in malodour and fluid handling were assessed with $89 \%$ of recruits rating the dressing's overall performance as very good to good.

\section{Developing new dressing technologies}

A versatile range of naturally-originated polymers including chitosan, hyaluronic acid, cellulose, alginate, dextran, collagen, gelatin, elastin, fibrin, and silk fibroin has been developed as wound dressings recently. ${ }^{46}$ These polymers have been used in the form of hydrogels, films, hydrocolloids, foams, membranes, scaffolds, micro-particles, and nano-particles for wounds and can play a role in wound exudate management, while at the same time enhancing wound healing by delivery of essential wound modulatory peptides and anti-bacterial drugs. Chitosan is the newest naturally occurring polymer that has been potentially developed into forms of dressings that can deliver inflamation regulatory peptides such as neurotensin to accelerate wound healing. ${ }^{47}$

\section{Discussion}

Gelling fiber dressings have been widely used as primary dressings to treat chronic and acute wounds for several decades. As it stands today, they are the mainstay of managing wound exudate and some also contribute further by trapping micro-organisms and preventing wound infections. A useful clinical resource to manage wound exudate is the consensus document on wound exudate management by the "World Union of Wound Healing Societies". ${ }^{14}$ In general, the dressing recommendations for heavily exuding wounds are dressing foams, absorbent gel forming agent dressings, and super-absorbent polymers. Deep cavity wounds should be packed with a dressing material appropriate for exudate level in rope, ribbon or strip form, thus eliminating the dead space. High tensile strength dressing material should be used to prevent retained dressings due to breakage or disintegration in deep cavities. NPWT is reserved in the management of deep wounds, particularly if exudate levels are high. Regular wound dressings can be recommenced when deeper cavities have healed. In wounds with malodour, the underlying cause such as necrotic tissue should be debrided and antimicrobial treatment started if the wound is infected. Dressings containing charcoal may help to absorb odour. NPWT devices with charcoal filters attached to the canister help odour management in deeper wounds. Protection of peri-wound skin with barrier films, skin protectant application, is as important as exudate management and should not be overlooked.

Evidence remains equivocal for recommending one dressing over the other in managing wound exudate and in our opinion, based on the studies, all three types of gelling fiber dressings are useful in wound treatment. Some of the salient points from NICE recommendations ${ }^{21}$ are as follows:

- meticulous clinical assessment based on wound characteristics, the clinical condition, and patient's experience with previous types of dressings is the key in choosing the right wound dressing.

- Cost-effective strategies taking into account the cost of the dressing, frequency of dressing changes, size of the wound, and shelf life of the dressing must be used while making dressing choices to avoid wastage and stockpiling.

- Anti-bacterial dressings (usually more expensive) should only be used when there are clinical signs of infection and if there are definite clinical indications.

NICE also recommends further research in this field with the aim of generating robust evidence for the use of advanced dressings. Gelling fiber dressings account for nearly $40 \%$ of the money spent on wound care products and it seems logical that further research should be directed here. However, as we see in practice, wounds present so much clinical variance that designing a research study to establish the best dressing is a formidable task. Wounds not only vary from person to person, but also show a different clinical picture with time, and dressings used 
can only cater to the wound characteristics at the time the clinician sees the wound. This is probably the reason why most studies have taken the form of dressing evaluations in cohorts and cases rather than stringently designed comparative randomized controlled trials.

Clinical evaluation reports based on the available clinical intelligence would be extremely helpful to clinicians and commissioners of health care. The "NHS Business Service Authority" in collaboration with their clinical evaluation team has recently produced one such document on CMC hydrofiber dressings that gives relevant information for reference to clinicians, commissioners, and stakeholders. ${ }^{24}$ They present a product assessment matrix showing all products with their brand names and their scores against the defined clinical criteria.

We also recommend using clinical experience as a factor for dressing choice. For example, in one study ${ }^{38}$ presented in the previous sections, the investigators used alginate and foam dressings sequentially with good results. The wounds were carefully selected pressure ulcers in spina-bifida patients. Every wound unit will have experience of both good and bad outcomes with different types of dressings in different types of wounds and patients. If it is certain that these outcomes relate to the dressing choices rather than other underlying factors, then this should be noted in patients' clinical records and/or in patients' treatment diary for future reference.

\section{Conclusion}

Gelling fiber dressings are widely used in clinical practice for moderate to heavily exuding wounds and have been on the market for over 20 years. Currently three classes of gelling fibers are available; two manufactured from naturally occurring agents, ie, alginate and chitosan and one synthetic gelling fiber, ie, CMC. High quality evidence to guide clinical use of gelling fibers is still lacking. However, existing literature on gelling fibers along with its wide clinical utility, suggests that these dressings are useful in managing wounds, especially heavily exuding wounds. Hence, the use of gelling fiber dressings must be guided by factors such as cost-effectiveness, the clinical type of wound, clinicians' experience, and patient factors. Further well-designed research, to test the performance of gelling fibers in managing wounds, is certainly justified.

\section{Disclosure}

The authors report no conflicts of interest in this work.

\section{References}

1. Wicke C, Bachinger A, Coerper S, Beckert S, Witte MB, Konigsrainer A. Aging influences wound healing in patients with chronic lower extremity wounds treated in a specialized Wound Care Center. Wound Repair Regen. 2009;17(1):25-33. doi:10.1111/ j.1524-475X.2008.00438.x

2. Frykberg RG, Banks J. Challenges in the treatment of chronic wounds. In Adv Wound Care (New Rochelle). Vol. 4; 2015;4 (9):560-582. doi:10.1089/wound.2015.0635

3. Phillips CJ, Humphreys I, Fletcher J, Harding K, Chamberlain G, Macey S. Estimating the costs associated with the management of patients with chronic wounds using linked routine data. Int Wound J. 2016;13(6):1193-1197. doi:10.1111/iwj.12443

4. Posnett J, Franks PJ. The burden of chronic wounds in the UK. Nurs Times. 2008;104(3):44-45.

5. Sen CK, Gordillo GM, Roy S, et al. Human skin wounds: a major and snowballing threat to public health and the economy. Wound Repair Regen. 2009;17(6):763-771. doi:10.1111/j.1524475X.2009.00543.X

6. Guest JF, Ayoub N, McIlwraith T, et al. Health Economic Burden that Wounds Impose on the National Health Service in the UK. BMJ Open. 2015;5(12)

7. Mudge E, Orsted H. Wound infection and pain management. Wound Int. 2010;1(3):1-5.

8. Falanga V. Wound bed preparation and the role of enzymes: a case for multiple actions of therapeutic targets. Wounds. 2002;14:47-57.

9. Schultz GS, Sibbald RG, Falanga V, et al. Wound bed preparation: a systematic approach to wound management. Wound Repair Regen. 2003;11 Suppl 1(Suppl 1):S1-S28.

10. Junker JP, Kamel RA, Caterson E, Eriksson E. Clinical impact upon wound healing and inflammation in moist, wet, and dry environments. In Adv Wound Care (New Rochelle). Vol. 2; 2013;2(7):348356. doi: $10.1089 /$ wound 2012.0412

11. Goto T, Tamai N, Nakagami G, et al. Can wound exudate from venous leg ulcers measure wound pain status?: a pilot study. PLoS One. 2016;11. doi:10.1371/journal.pone.0167478

12. Gardner SE, Frantz RA, Doebbeling BN. The validity of the clinical signs and symptoms used to identify localized chronic wound infection. Wound Repair Regen. 2001;9(3):178-186.

13. Gray M, Black JM, Baharestani MM, et al. Moisture-associated skin damage: overview and pathophysiology. $J$ Wound Ostomy Continence Nurs. 2011;38(3):233-241. doi:10.1097/WON.0b013e318215f798

14. A World Union of Wound Healing Societies (WUWHS). Wound Exudate and the Role of Dressings: A Consensus Document. London: Medical Education Partnership (MEP) Ltd; 2007.

15. Nichols E. Wound assessment part 2: exudate. Wound Essentials. 2016;11(1):36-41.

16. 2018. Available from: https://www.cochrane.org/CD010318/ WOUNDS_negative-pressure-wound-therapy-treating-foot-woundspeople-diabetes-mellitus. Accessed October 17, 2018.

17. Dumville JC, Land L, Evans D, Peinemann F. Negative pressure wound therapy for treating leg ulcers. Cochrane Database Syst Rev. 2015;(7):CD011354.

18. Dumville JC, Webster J, Evans D, Land L. Negative pressure wound therapy for treating pressure ulcers. Cochrane Database Syst Rev. 2015;(5):CD011334.

19. Majno G. The Healing Hand: Man and Wound in the Ancient World. 1st paperback ed. Cambridge, MA: Harvard University Press; 1991.

20. Jones VJ. The use of gauze: will it ever change? Int Wound J. 2006;3 (2):79-86

21. National Institute of Clinical Excellence- NICE. Chronic wounds: advanced wound dressings and antimicrobial dressings | guidance and guidelines | NICE. March 2016. Available from: https://www. nice.org.uk/advice/esmpb2/chapter/Key-points-from-the-evidence. Accessed October 14, 2018 
22. Waring MJ, Parsons D. Physico-chemical characterisation of carboxymethylated spun cellulose fibres. Biomaterials. 2001;22(9):903-912.

23. Sood A, Granick MS, Tomaselli NL. Wound dressings and comparative effectiveness data. Adv Wound Care (New Rochelle). 2014;3:511-529. doi:10.1089/wound.2012.0401

24. Available from https://www.supplychain.nhs.uk/product-news/publications/clinical-evaluation-reports/ /media/Files/BSA $\%$ 20Documents/NHS\%20CET\%20Reports/Clinical\%20Review\% 20Gelling\%20Fibre\%20Dressings.ashx. Accessed May 03, 2019.

25. Armstrong SH, Ruckley CV. Use of a fibrous dressing in exuding leg ulcers. J Wound Care. 1997;6(7):322-324.

26. Ravnskog FA, Espehaug B, Indrekvam K. Randomised clinical trial comparing hydrofiber and alginate dressings post-hip replacement. J Wound Care. 2011;20(3):136-142. doi:10.12968/ jowc.2011.20.3.136

27. Welch D, Hepworth L, Barrett S, Overfield J, Forder R. Clinical evaluation of the effect of ActivHeal Aquafiber ${ }^{\circledR} \mathrm{Ag}$ dressing. Wounds UK. 2017;13:1.

28. Forlee M, Rossington A, Searle R. A prospective, open, multicentre study to evaluate a new gelling fibre dressing containing silver in the management of venous leg ulcers. Int Wound J. 2014;11(4):438-445. doi:10.1111/iwj.12239

29. Jones N, Ivins N, Ebdon V, Hagelstein S, Harding K. A case series evaluating the use of a gelling fibre dressing for moderate to highly exuding wounds. Wounds UK. 2017;13:1.

30. Ivins N, Braumann C, Kirchhoff JB, Waldemar U, Jones NJ. Use of a gelling fibre dressing in complex surgical or chronic wounds: a case series. J Wound Care. 2018;27(7):444-454. doi:10.12968/ jowc.2018.27.7.444

31. Russell L, Carr J. New hydrofibre and hydrocolloid dressings for chronic wounds. J Wound Care. 2000;9(4):169-172. doi:10.12968/ jowc.2000.9.4.25969

32. Timmons J. Alginates and hydrofibre dressings. Prof Nurse. 1999;14 (7):496-499, 501, 503 .

33. Attwood AI. Calcium alginate dressing accelerates split skin graft donor site healing. Br J Plast Surg. 1989;42(4):373-379.

34. Steenfos HH, Agren MS. A fibre-free alginate dressing in the treatment of split thickness skin graft donor sites. J Eur Acad Dermatol Venereol. 1998;11(3):252-256.

35. Terrill PJ, Goh RC, Bailey MJ. Split-thickness skin graft donor sites: a comparative study of two absorbent dressings. J Wound Care. 2007;16(10):433-438. doi:10.12968/jowc.2007.16.10.27912
36. Berry DP, Bale S, Harding KG. Dressings for treating cavity wounds. $J$ Wound Care. 1996;5(1):10-17.

37. Bale S, Baker N, Crook H, Rayman A, Rayman G, Harding KG. Exploring the use of an alginate dressing for diabetic foot ulcers. $J$ Wound Care. 2001;10(3):81-84. doi:10.12968/jowc.2001.10.3.26063

38. Ausili E, Paolucci V, Triarico S, et al. Treatment of pressure sores in spina bifida patients with calcium alginate and foam dressings. Eur Rev Med Pharmacol Sci. 2013;17(12):1642-1647.

39. Azuma K, Izumi R, Osaki T, et al. Chitin, chitosan, and its derivatives for wound healing: old and new materials. J Funct Biomater. 2015;6:104-142. doi:10.3390/jfb6010104

40. Kumar PS, Raj NM, Praveen G, Chennazhi KP, Nair SV, Jayakumar $\mathrm{R}$. In vitro and in vivo evaluation of microporous chitosan hydrogel/ nanofibrin composite bandage for skin tissue regeneration. Tissue Eng Part A. 2013;19:380-392. doi:10.1089/ten.TEA.2012.0376

41. Kordestani S, Shahrezaee M, Tahmasebi MN, Hajimahmodi H, Haji Ghasemali D, Abyaneh MS. A randomised controlled trial on the effectiveness of an advanced wound dressing used in Iran. $J$ Wound Care. 2008;17(7):323-327. doi:10.12968/jowc.2008.17.7.30525

42. Bennett J, Thompson J. Deep bone infections following surgery. $\mathrm{Br} \mathrm{J}$ Nurs. 2015;24(6):S24. doi:10.12968/bjon.2015.24.Sup6.S24

43. Walker A. Podiatry evaluation of a chitosan gelling fibre dressing in diabetic foot ulceration. Br $J$ Nurs. 2016;25(12):S51-S58. doi:10.12968/bjon.2016.25.12.S51

44. Orig R, Singleton J. A non-comparative evaluation of a chitosan gelling fibre. $\mathrm{Br} J$ Nurs. 2016;25(3):162-170. doi:10.12968/ bjon.2016.25.3.162

45. Mason S, Clarke C. A multicentred cohort evaluation of a chitosan gelling fibre dressing. $\mathrm{Br} J$ Nurs. 2015;24(17):868,870-866. doi:10.12968/bjon.2015.24.17.868

46. Hussain Z, Thu HE, Shuid AN, Katas H, Hussain F. Recent advances in polymer-based wound dressings for the treatment of diabetic foot ulcer: an overview of state-of-the-art. Curr Drug Targets. 2018;19 (5):527-550. doi:10.2174/1389450118666170704132523

47. Moura LI, Dias AM, Leal EC, Carvalho L, de Sousa HC, Carvalho E. Chitosan-based dressings loaded with neurotensin-an efficient strategy to improve early diabetic wound healing. Acta Biomater. 2014;10 (2):843-857. doi:10.1016/j.actbio.2013.09.040
Chronic Wound Care Management and Research

\section{Publish your work in this journal}

Chronic Wound Care Management and Research is an international, peer reviewed, open access, online journal publishing original research, reviews, editorials, and commentaries on the causes and management of chronic wounds and the major issues related to chronic wound management. Topics also include chronic wounds as comorbidities to other conditions, patient adherence to therapy, and the economic burden of chronic wounds. The manuscript management system is completely online and includes a very quick and fair peer review system, which is all easy to use. Visit http://www.dovepress.com/ testimonials.php to read real quotes from published authors. 